\title{
NUEVA TERAPIA CON INMUNOGLOBULINAS EN UN CASO DE HEMOCROMATOSIS NEONATAL
}

\author{
1 Mireia Cruceyra Betriu, ${ }^{1}$ Nuria Martínez Sánchez, ${ }^{1}$ María De la Calle Fernández- \\ Miranda, ${ }^{1}$ María del Mar González Arlanzón, ${ }^{2}$ Aurora Viejo Llorente, ${ }^{3}$ Esteban Frauca \\ Remacha, ${ }^{1}$ Antonio González González. \\ ${ }^{1}$ Servicio de Obstetricia y Ginecología, ${ }^{2}$ Servicio de Hematología. ${ }^{3}$ Servicio de Pediatría, Hospital Universitario La Paz, \\ Madrid, España.
}

\section{RESUMEN}

La hemocromatosis neonatal es una enfermedad hepática muy severa del recién nacido y se asocia a una alta mortalidad. Se cree que su etiología es de tipo aloinmune, debido a la presencia de un anticuerpo materno hasta ahora desconocido que interfiere con el metabolismo férrico del feto, llegando a producir gran morbimortalidad. Basándonos en esta teoría, el tratamiento materno con inmunoglobulinas intravenosas en gestaciones sucesivas podría prevenir el desarrollo de un nuevo cuadro de hemocromatosis neonatal. Se describe el caso de una gestante con un hijo anterior diagnosticado y fallecido neonatalmente por hemocromatosis, a la que en el embarazo actual se le trató con inmunoglobulinas intravenosas consiguiendo un hijo sano y vivo. Es el primer caso descrito en España y demuestra el éxito de esta terapia, tal como describe la literatura.

\section{PALABRAS CLAVE: Hemocromatosis neonatal, inmunoglobulinas, enfermedad hepática neonatal aloinmune}

\section{SUMMARY}

Neonatal hemochromatosis is a severe neonatal liver disease with a high mortality and recurrence rate. It is supposed to be a gestational alloimmune disease because of the existence of maternal antibodies against fetal hepatic metabolism. On the basis of this hypothesis, the administration of intravenous immunoglobulin has been reported as a successful treatment during the following pregnancy. We describe the first case of this treatment in Spain which confirms the data available in the literature.

KEY WORDS: Neonatal hemochromatosis, immunoglobulin, neonatal alloimmune liver disease

\section{INTRODUCCIÓN}

La hemocromatosis neonatal (HN) es una extraña enfermedad congénita cuyas manifestaciones clínicas son una severa afectación de la función hepática asociada a hemosiderosis hepática y extrahepática $(1,2)$.
La HN presenta una baja incidencia (3), sin embargo, es la causa más frecuente de fallo hepático en el recién nacido y la indicación más común de trasplante hepático en los primeros tres meses de vida (3).

La etiopatogenia de la $\mathrm{HN}$ todavía no se conoce, y aunque se han postulado diversas teorías 
(infecciones, tóxicos, genético, metabólico), la que ha cobrado mayor importancia en los útimos años es la teoría aloinmune (4). Esta teoría se basa en la existencia de un anticuerpo materno de tipo lgG, aún por determinar, que al atravesar la placenta, se dirigiría contra el hígado fetal interfiriendo con el metabolismo férrico.

Existen varios factores asociados a la enfermedad que apoyarían este origen aloinmune. En primer lugar, la $\mathrm{HN}$ tiene un inusual y alto índice de recurrencia. La descendencia de una mujer con un hijo previo afecto tiene hasta el $80 \%$ de probabilidades de sufrir la enfermedad; siendo este índice demasiado alto como para ser explicado según los patrones de herencia mendeliana $(1,5)$. En segundo lugar, no existían antecedentes familiares de la enfermedad en ningún caso. Otro aspecto importante, es que mientras que los hombres no vuelven a tener hijos afectos si cambian de pareja, esto sí sucede en las mujeres, que tienen hijos afectados con diferentes parejas. Por último, el patrón de recurrencia se asemeja al de aquellas enfermedades gestacionales aloinmunes establecidas como la enfermedad hemolítica perinatal y la trombocitopenia aloinmune (4). Todo esto y la falta de evidencia de otras etiologías conducen a la aceptación cada vez mayor de la teoría aloinmune como causa de la HN.

Basándose en esta teoría, se establece el tratamiento materno con inmunogobulinas. Se trata de un tratamiento empírico con inmunoglobulinas intravenosas a partir de la semana 18 de gestación, que se administran en gestantes con un antecedente de un hijo previo con HN. El momento del inicio del tratamiento con inmunoglobulinas se ha establecido en la semana 18, porque es cuando comienza el transporte de las mismas a través de la placenta. La dosis propuesta en la literatura es de $1 \mathrm{~g} / \mathrm{kg}$ semanal hasta el final del embarazo $(5,6)$.

El mecanismo de acción de las inmunoglobulinas se lleva a cabo de tres formas: bloqueando la respuesta inmune materna a los antígenos fetales, produciendo una saturación del mecanismo de transporte placentario de la IgG con anticuerpos inespecíficos, y a través de la unión de los anticuerpos inespecíficos con los antígenos fetales impidiendo así la unión de los anticuerpos aloinmunes reactivos (7).

La literatura actual demuestra el éxito de la terapia con inmunoglobulinas obteniendo unos excelentes resultados perinatales en comparación a los obtenidos con las terapias convencionales con antioxidantes o quelantes del hierro (1).

\section{Caso clínico}

Gestante tercigesta de 28 años con antecedente de un parto normal con un hijo vivo en el año 2004, y otro parto vaginal con un recién nacido que falleció al mes y medio de vida en el año 2007. Dicho recién nacido fue trasladado al mes y 4 días de vida a la unidad de Cuidados Intensivos Neonatales del Hospital La Paz de Madrid, presentando signos evidentes de fallo hepático sin un diagnóstico claro del origen. Tras descartar la etiología infecciosa como probable causa del fallo hepático, se le realizó una sesión de exanguinotransfusión, tratamiento con antioxidantes y quelantes del hierro. Fue candidato a trasplante hepático, falleciendo el día 22 de ingreso por fallo multiorgánico, sin haber encontrado donante disponible. La necropsia del recién nacido, confirmó el diagnóstico de sospecha de HN, observándose depósito multivisceral de hierro en hígado, corazón, páncreas, tiroides y más débilmente en paratiroides y suprarrenales.

En 2008 la paciente es derivada de nuevo a nuestro Hospital, a la Unidad de Tocología de Alto Riesgo, por presentar una nueva gestación. Los controles analíticos y ecográficos del primer trimestre son normales. En la semana 16 se realiza una amniocentesis con resultado normal de cariotipo masculino 46XY.

Tras una revisión exhaustiva de la literatura sobre la $\mathrm{HN}$ y por su alta tasa de recurrencia en gestaciones posteriores, en sesión multidisciplinaria (Servicios de Obstetricia, Hematología y Pediatría) se decide conjuntamente el tratamiento de la gestante con altas dosis de inmnunoglobulinas intravenosas, dados los esperanzadores resultados descritos.

A partir de la semana 18 de embarazo, se inicia la administración semanal de $1 \mathrm{~g}$ de inmunoglobulinas intravenosas por kilogramo de peso en infusión lenta (6 horas) para evitar reacciones alérgicas. Con el mismo fin, una hora antes de dicho tratamiento se le suministra una premedicación consistente en $100 \mathrm{mg}$ de hidrocortisona, 1 ampolla iv de dexclorferinamina y $1 \mathrm{~g}$ iv de paracetamol.

Se realizan controles ecográficos y analíticos a lo largo de la gestación siendo normales. Los ultrasonidos muestran un hígado fetal con una ecogenicidad homogénea de aspecto normal. El tratamiento con inmunoglobulinas se administra semanalmente hasta la semana 38 , en la que se produce el parto, que se desarrolla de forma eutócica, naciendo un varón de 2.850 gramos. La valoración 
neonatal inmediata muestra un Apgar 7-9, con un $\mathrm{pH}$ en arteria umbilical 7,34 y reanimación tipo III. EI recién nacido presenta un cuadro de distrés respiratorio inmediato con maladaptación pulmonar por lo que precisa tratamiento con diuréticos y dispositivo de presión positiva en vía aérea (CPAP) durante 48 horas. Ante el riesgo de desarrollar hemocromatosis neonatal se le administran inmunoglobulinas intravenosas a razón de $1 \mathrm{~g} / \mathrm{kg}$ de peso el primer día y $0,5 \mathrm{~g} / \mathrm{kg}$ los tres días siguientes, además de $\mathrm{N}$-acetilcisteína.

El recién nacido evoluciona en buenas condiciones y es dado de alta al cuarto día de vida sin signos de afectación hepática, ni alteración en el metabolismo del hierro. Se realiza un último control a los 3 meses de vida siendo todas las pruebas normales.

\section{DISCUSIÓN}

La HN continúa siendo una enfermedad catalogada como "rara", tanto por su baja prevalencia como por su origen desconocido. De acuerdo con la teoría aloinmune, y de la misma forma que en las enfermedades aloinmunes gestacionales más conocidas como la isoinmunización Rh y la trombopenia autoinmune, se generarían anticuerpos maternos contra un antígeno hepático fetal que atacarían al hígado del feto produciendo las manifestaciones clínicas de la enfermedad.

El objetivo en el futuro sería lograr identificar dicho antígeno y así poder diseñar un test serológico para el diagnóstico de la HN. Dicho test permitiría diagnosticar la enfermedad en la madre antes que en el recién nacido, pudiendo aplicar tratamientos profilácticos y no paliativos en el hijo afecto (4). Se dispondría así de una herramienta para identificar a las mujeres con riesgo de tener hijos afectos de $\mathrm{HN}$, que podrían ser tratadas antes de que eso ocurra, de manera similar al manejo de las gestantes Rh negativas.
De momento, y a la espera de la aparición de una prueba diagnóstica precoz, la terapia materna con inmunoglobulinas ha demostrado ser la más eficaz para evitar la $\mathrm{HN}$ tal y como ponemos de manifiesto en nuestro caso. Este es el primer caso publicado en España y se añade a la escasa lista de casos exitosos publicados en la literatura mundial, corroborando así la teoría aloinmune como etiología de la $\mathrm{HN}$.

\section{CONCLUSIÓN}

Hacen falta más estudios que nos orienten a identificar a las gestantes con riesgo y en ellas poder establecer un protocolo de actuación con seguimiento específico serológico, ecográfico y terapéutico en caso necesario.

\section{BIBLIOGRAFÍA}

1. Whitington PF, Kelly S. Outcome of pregnancies at risk for neonatal hemochromatosis is improved by treatment with high-dose intravenous immunoglobulins. Pediatrics 2008;121(6):1615-21.

2. Knisely AS, Mieli-Vergani G, Whitington PF. Neonatal hemochromatosis. Gastroenterol Clin North Am 2003;32:877-89.

3. Sundaram SS, Alonso EM, Whitington PF. Liver transplantation in neonates. Liver Transpl 2003;9:783-8.

4. Whitington PF, Padmini M. Neonatal hemochromatosis: is it an alloimmune disease?J Pediatr Gastroenterol Nutr 2005;40:544-9.

5. Whitington PF, Hibbard JU. High-dose immunoglobulin during pregnancy for recurrent neonatal haemochromatosis. Lancet 2004;364:1690-8.

6. Timpani G, Foti F, Nicolò A, Nicotina PA, Nicastro $E$, lorio $R$. Is exchange transfusion a possible treatment for neonatal hemochromatosis? J Hepatol 2007;47(5):732-5.

7. Kazatchkine MD, Kaveri SV. Immunomodulation of autoimmune and inflammatory diseases with intravenous immuneglobulin. N Engl J Med 2001;345(10):747-55. 